\title{
Forgotten drugs: long-term prescriptions of thyroid hormones - a cross-sectional study
}

This article was published in the following Dove Press journal:

International Journal of General Medicine

25 April 2013

Number of times this article has been viewed

\section{Annika Viniol \\ Stefan Bösner \\ Erika Baum \\ Norbert Donner-Banzhoff \\ Department of General Practice/ Family Medicine, Philipps University of Marburg, Marburg, Germany}

Background: Thyroid hormones are among the most prescribed drugs in Germany. Although iodine supply has been improving in the last decade, annual prescriptions for thyroid hormones are rising. The aim of this study was to provide prevalence of thyroid hormone prescribing and to explore reasons for thyroid hormone prescription in primary care settings.

Study design: A cross-sectional study.

Methods: Data collection took place in six general practitioner (GP) practices in Hesse, Germany. We used the records of six GP practices to estimate prevalence of thyroid hormone prescribing. All patients who received a prescription of the active ingredient levotyroxine during the preceding 3 months were mailed a study invitation. A proportion of the identified patients were interviewed. In addition, demographical data and all medical findings related to thyroid disease were recorded.

Results: On average, 9.2\% (SD 4.6) of all patients from participating practices were taking thyroid hormones. The majority were female (82.5\%). In $47.7 \%$ of the study participants, the GP's diagnosis, according to their records, was nonexistent. In $13.6 \%$ of cases, the documentation of the diagnostic information was incomplete. While $25 \%$ of interviewed patients with high educational background initiated further diagnostic investigation, only $4.4 \%$ of the patients with lower education did so.

Conclusion: In the majority of patients treated with thyroid hormones, doctors had not documented the precise indication for prescription.

Keywords: thyroid hormones, represcription, primary health care

\section{Background}

Thyroid hormones are among the most prescribed drugs in Germany. ${ }^{1}$ According to the German National Health Survey, the prevalence for thyroid hormone intake is $5.1 \%{ }^{2}$ Although iodine supply has been improving over the last decade, ${ }^{3,4}$ annual prescription rates for thyroid hormones are rising. ${ }^{2}$ According to current research, the indication for thyroid hormones in cases of euthyroid, diffuse, and endemic goiter is still controversial. $^{5-9}$ Additional factors for high prescription rates could be the economic motives of doctors and the pharmaceutical industry, as well as patient- and physician-related psychological factors.

\section{Objectives}

In the study we aimed to answer the following research questions: Why do patients take thyroid hormones (doctor and patient view)? Which situations lead to the establishment 
of the diagnosis “thyroid disease?" How do patients perceive the regular intake of thyroid hormone?

\section{Methods}

\section{Study design}

This is a cross-sectional study about the intake of thyroid hormones in primary care.

\section{Recruitment}

We selected a convenience sample of six medical practices of differing sizes from both urban and rural locations having varying organizational structures (solo/group practices). We used practice management software to find all patients who had received a thyroid hormone prescription, independent from office visits, during the preceding 3-month period. Therefore, we estimated prevalence of thyroid hormone prescribing in primary care practices. Prevalence of prescribing was the percentage portion of patients who had received a prescription of active ingredient levotyroxine in relation to all patients who visited the practice (direct office visits + indirect contacts for getting prescriptions, without seeing the doctor), in the preceding 3-month period. All identified thyroid hormone patients received recruitment letters in August 2008. Every patient who was allowed participation was interviewed. We aimed for a sample size of 200 participants, which was calculated by the method of Lemeshow et al. ${ }^{10}$

\section{Data collection and instruments}

After written consent had been obtained, patient interviews took place over a time period of 6 months (October 2008 to April 2009). One interviewer conducted standardized interviews using a semi-structured questionnaire, which was designed and tested beforehand during a test run. The questionnaire contained the following information: time of medication intake; preparation and dosage; reason for thyroid hormone intake; symptoms both at the time of diagnosis and after starting therapy; adverse reactions; level of doctors' involvement in thyroid disease-related treatment; disadvantages of thyroid hormones; and patient concerns with regard to withdrawal of medication. All questions were coded with preassigned variables. Interview data were analysed quantitatively by one researcher. Furthermore, all medical findings related to the thyroid gland, co-medications, and demographical data of the patients were recorded.

For every case we assessed whether the GP's records contained diagnostic information that justified therapy (all thyroid disease-related letters from specialists and general practitioner [GP] notes including thyroid function tests).
The diagnostic information that justified therapy was rated "complete" when records contained information about metabolic status (hypothyroid/euthyroid/hyperthyroid), morphologic alterations (yes/no), and size of thyroid gland (yes/no). The term "morphologic alterations" referred to every kind of expansion lesion (generally nodules or cysts) seen in ultrasound or palpabled in clinical examination. The information was rated "incomplete" when one of these three parameter values was missing. The category "nonexistent" was rated when GP records do not contain any diagnostic information.

During interviews, we asked open questions about the natural course of the patient's disease. We classified every patient in one of five typical situations describing how the diagnosis was established. The typical situations were found in a qualitative evaluation of the interviews in a preliminary test run.

Similarly, four typical patient reactions when confronted with the scenario of medication withdrawal were found in the test run. Every patient was assigned to one of four typical reaction categories (Table 3 ).

For calculation of interrater agreement, we also coded the patient's information about their thyroid disease in three categories (metabolic status, morphologic alteration, and enlarged thyroid gland).

\section{Statistical analysis}

All data were coded and entered into an anonymous database. For univariate comparisons of categorical data we used the chi-square test. The $t$-test was used for comparing means. For measurement of interrater agreement we applied

Table I Situations that led to thyroid disease diagnosis $(n=214)$

\begin{tabular}{|c|c|c|c|}
\hline $\begin{array}{l}\text { Situation } \\
\text { number }\end{array}$ & Definition & $n$ & $\%$ \\
\hline I & $\begin{array}{l}\text { Diagnosis by chance following a blood test } \\
\text { in the context of a health checkup. } \\
\text { No clinical signs of thyroid disease. }\end{array}$ & 43 & 20.1 \\
\hline 2 & $\begin{array}{l}\text { Patient went to the doctor because of } \\
\text { symptoms or self-detected morphologic } \\
\text { alterations, although not relating them to } \\
\text { thyroid disease. The doctor started the } \\
\text { diagnostic investigation. }\end{array}$ & 112 & 52.3 \\
\hline 3 & $\begin{array}{l}\text { The doctor noticed an enlarged thyroid gland } \\
\text { during a routine consultation. The doctor } \\
\text { started the diagnostic investigation. }\end{array}$ & 22 & 10.3 \\
\hline 4 & $\begin{array}{l}\text { Patient was concerned about thyroid disease, } \\
\text { irrespective of existing symptoms. } \\
\text { Patient demanded further investigation. }\end{array}$ & 29 & 13.6 \\
\hline 5 & Classification into categories I-4 not possible & 8 & 3.7 \\
\hline
\end{tabular}

Notes: an Germany, thyroid blood parameters do not belong to "the catalogue of benefit of the health insurance fund for health check-up" of the German Federal Joint Committee of doctors and health insurance funds. ${ }^{16}$ 
Cohen's kappa coefficient. The normal distribution was tested with the Kolmogorov-Smirnov test. All statistical analyses were performed with SPSS software (v 15.0; IBM Corporation, Armonk, NY, USA).

\section{Ethics approval}

The study was approved by the local ethics commission of Philipps University of Marburg, Marburg, Germany, and is in accordance with the Declaration of Helsinki.

\section{Results}

\section{Patients}

We identified 887 patients who receive permanent prescriptions of thyroid hormones. On average, 9.23\% (SD 4.6) of all patients in the participating practices were taking thyroid hormones. The majority of these were female $(82.7 \%)$. Of the identified patients, 214 (24.1\%) were eligible for participation and were interviewed. Patient characteristics are shown in Table 2.

The comparison between participants available for detailed interview and nonparticipants showed no genderspecific differences. On average, participants were 3 years older than nonparticipants.

\section{Reasons for thyroid hormone intake (patient's point of view)}

A total of 129 patients remembered their metabolic status at the time of diagnosis. Of these, $72.1 \%$ quoted hypothyroidism (euthyroid 13.2\%; hyperthyroid 14.7\%). A total of 205 participants remembered morphologic alterations. Of these, $63.4 \%$ had a nodule or cyst. A total of 202 patients could give detailed information about their thyroid gland size. Of these, $64.4 \%$ had an enlarged thyroid gland at the time of diagnosis.

Table 2 Patient characteristics of interview sample $(n=214)$

\begin{tabular}{|c|c|c|}
\hline & Number (n) & Percentage (\%) \\
\hline \multicolumn{3}{|l|}{$\operatorname{Sex}(n=2 \mid 4)$} \\
\hline Female & 177 & 82.7 \\
\hline Male & 37 & 17.3 \\
\hline \multicolumn{3}{|l|}{ Age (years) $(n=214)$} \\
\hline $0-20$ & 0 & 0 \\
\hline $21-40$ & 23 & 10.7 \\
\hline $4 I-60$ & 81 & 37.9 \\
\hline $61-80$ & 101 & 47.2 \\
\hline$>80$ & 9 & 4.2 \\
\hline \multicolumn{3}{|c|}{ Education level $(n=209)$} \\
\hline Lower education ${ }^{\mathrm{a}}$ & 113 & 54.1 \\
\hline Higher education $^{\mathrm{b}}$ & 96 & 45.9 \\
\hline
\end{tabular}

Notes: aLower education: $\leq$ Certificate of Secondary Education (CSE); bhigher education: $\geq 0$-levels.
Interrater agreement between doctors and patients: reasons for thyroid hormone intake

For morphologic alterations, we noted the highest accordance between doctors and patients $(\mathrm{k}=0.654$; standard error $[\mathrm{SE}]=0.084 ; \mathrm{n}=89$ ). For thyroid gland increase, the accordance was moderate $(\mathrm{k}=0.488 ; \mathrm{SE}=0.096 ; \mathrm{n}=85)$ and low for the metabolic status $(\mathrm{k}=0.334 ; \mathrm{SE}=0.084 ; \mathrm{n}=58)$.

\section{Symptoms at time of diagnosis}

At the time of diagnosis, $31.3 \%$ of patients had never experienced thyroid disease-related clinical symptoms. However, $36.9 \%$ had one or two symptoms, while $31.8 \%$ had more than three symptoms at the time of diagnosis.

\section{Reasons for thyroid hormone intake (doctor's point of view)}

In $47.7 \%$ of the study participants the GP's diagnosis, according to their records, was nonexistent. In $13.6 \%$ of cases, the documentation of the diagnostic information was incomplete (Table 3). In 38.8\% of patients, GPs had all necessary diagnostic information available to justify the therapy.

\section{Situations that led to thyroid disease diagnosis}

Half of the patients went to their doctor because of symptoms or self-detected morphologic alterations, although not relating them to thyroid disease. The doctor started the diagnostic investigation (Table 1). A total of $20.1 \%$ of participants were diagnosed by chance, mainly during health checkups, even though the thyroid blood parameters do not belong to "the catalogue of benefit of the health insurance fund for health check-up" in Germany. ${ }^{16} \mathrm{~A}$ total of $13.6 \%$ of the patients were concerned about thyroid disease, irrespective of existing symptoms, and initiated further investigation themselves.

Table 3 Completeness of general practitioner (GP) records in regards to therapy with thyroid hormones $(n=214)$

\begin{tabular}{llll}
\hline $\begin{array}{l}\text { Information } \\
\text { is ... }\end{array}$ & Definition & $\begin{array}{l}\text { Number } \\
\text { (n) }\end{array}$ & $\begin{array}{l}\text { Percent } \\
\text { (\%) }\end{array}$ \\
\hline$\ldots$ complete & $\begin{array}{l}\text { GP records contain } \\
\text { diagnostic information } \\
\text { that justifies therapy. }\end{array}$ & 83 & 38.8 \\
$\ldots$ incomplete & $\begin{array}{l}\text { GP records do not contain } \\
\text { sufficient diagnostic } \\
\text { information to justify therapy. }\end{array}$ & 29 & 13.6 \\
$\ldots$ nonexistent & $\begin{array}{l}\text { GP records do not contain } \\
\text { any diagnostic information } \\
\text { to justify therapy. }\end{array}$ & 102 & 47.7 \\
\hline
\end{tabular}


In $10.3 \%$ of patients, the doctor noticed an enlarged thyroid gland during a routine consultation.

\section{Correlation between educational background and the establishment of diagnosis}

While $25 \%$ of study participants with high educational background (O-levels [highest possible high school degree] or higher) initiated further diagnostic investigation, only $4.4 \%$ of the patients with lower education (Certificate of Secondary Education [CSE] or lower) did so. Patients with lower education more often got their diagnosis by visiting the doctor because of symptoms or self-detected morphologic alterations, although not relating them to thyroid disease, in which the doctor started the diagnostic investigation. Patients with higher education more often got their diagnosis because of concern about thyroid disease irrespective of existing symptoms, and demanded further investigation (Table 4). No fundamental differences between the two educational groups were found in the remaining three categories for establishment of diagnosis.

\section{Patient perceptions about regular intake of thyroid hormones}

We found different patient reactions when confronted with the scenario of medication withdrawal. While $16.8 \%$ $(n=33)$ thought nothing would happen if the medication was withdrawn, 9.6\% $(n=19)$ of patients thought they would die (grave consequences). Most of the participants ( $43.7 \%, \mathrm{n}=86$ ) belonged to the category "symptoms that do not strongly influence the quality of life/daily routine not disturbed." A total of $29.9 \%(n=59)$ of participants expected symptoms that would influence the quality of life and disturb their daily routine. When asked "Do you think it could be of disadvantage to take thyroid hormones?", $83.6 \%$ gave a negative answer, but $16.4 \%$ had already thought about disadvantages.

\section{Discussion}

On average, $9 \%$ of all patients from the participating practices were taking thyroid hormones. For nearly half of the study participants, the GP's diagnosis, according to their records, was nonexistent; in more than one-tenth of the cases, the diagnosis details were incomplete. In onefifth of the study participants, thyroid disease had been diagnosed by chance following a blood test in the context of a health checkup. Illness perceptions and patient expectations during consultation depended on the educational background.

To our knowledge, this is the first study that critically questions the current prescription practice of thyroid hormones in Germany. This topic has political and economic relevance (financial savings from reduction of unnecessary prescriptions; role assignment in diagnosis and therapy of thyroid disease between specialists and GPs) for primary care.

With a total response rate of $24.1 \%$ for the interview part of our investigation, we cannot exclude a selection bias. However, this rate conforms with usual response rates for postal recruitment. ${ }^{11}$

We found a high rate of patients taking thyroid hormones who did not have clear documentation of the indication for the prescription in their medical record. The process of thyroid hormone prescription is governed by different actors, namely GPs, specialized doctors, patients, and the pharmaceutical industry. Aside from pure medical reasons, the interests and activities of the aforementioned stakeholders are based on economical and psychodynamic aspects: in Germany, patients with thyroid gland disease are treated by different medical specialities. GPs usually refer patients

Table 4 Educational background and establishment of diagnosis $(n=209)$

\begin{tabular}{|c|c|c|c|c|c|c|}
\hline $\begin{array}{l}\text { Educational } \\
\text { background }\end{array}$ & $\begin{array}{l}\text { Situation I } \\
\mathbf{n}(\%) \\
\text { Diagnosis } \\
\text { by chance }\end{array}$ & $\begin{array}{l}\text { Situation } 2 \\
\mathrm{n}(\%) \\
\text { Diagnosis initiated } \\
\text { by doctor because } \\
\text { of symptoms }\end{array}$ & $\begin{array}{l}\text { Situation } 3 \\
\text { n (\%) } \\
\text { Viewable } \\
\text { morphological } \\
\text { alteration }\end{array}$ & $\begin{array}{l}\text { Situation } 4 \\
\text { n (\%) } \\
\text { Diagnosis } \\
\text { initiated } \\
\text { by patient }\end{array}$ & $\begin{array}{l}\text { Situation } 5 \\
\mathrm{n}(\%) \\
\begin{array}{l}\text { Other } \\
\text { situations }\end{array}\end{array}$ & Total \\
\hline Lower & 23 & 68 & 14 & 5 & 3 & 113 \\
\hline education $^{\mathrm{a}}$ & $20.4 \%$ & $60.2 \%$ & $12.4 \%$ & $4.4 \%$ & $2.7 \%$ & $100 \%$ \\
\hline Higher & 18 & 43 & 7 & 24 & 4 & 96 \\
\hline education ${ }^{b}$ & $18.8 \%$ & $44.8 \%$ & $7.3 \%$ & $25.0 \%$ & $4.2 \%$ & $100 \%$ \\
\hline \multirow[t]{2}{*}{ Total } & 41 & 111 & 21 & 29 & 7 & 209 \\
\hline & $19.6 \%$ & $53.1 \%$ & $10.0 \%$ & $13.9 \%$ & $3.3 \%$ & $100 \%$ \\
\hline
\end{tabular}

Notes: aLower education: $\leq$ Certificate of Secondary Education (CSE); bhigher education: $\geq$ O-levels. $X^{2}=19.914, \mathrm{df}=4, P=0.00 \mathrm{I}$. 
with thyroid diseases to specialists for further examination (eg, ultrasound, thyroid scintigraphy, and special blood tests), diagnosis, and therapy recommendation. GPs then continue further therapy according to the recommendation of the specialist. Coordination of these different levels of care is challenging and may lead to loss of information. ${ }^{12}$ This may be one reason that the majority of our study patients' records did not contain diagnostic information justifying therapy. Furthermore, GPs in Germany do not archive patient documents longer than 10 years, ${ }^{13}$ and they are often lost after change of practice.

Thyroid hormones are usually prescribed lifelong. Balint et al found that diagnosis and its therapeutic consequences (represcription) could be a result of a difficult doctor-patient relationship. ${ }^{14}$ The result of doctor-patient contacts where patients exhibit unexplained medical symptoms are often unnecessary prescriptions or somatic investigations. ${ }^{15}$ One possible reason for patients to receive a prescription for a thyroid hormone without a clear, definite diagnosis to support the prescription could be that patients presented to their physician with unexplained medical symptoms and were prescribed thyroid hormone as an intervention.

In one-fifth of the study participants thyroid disease was diagnosed by chance following a blood test in the context of a health checkup. This is significant as thyroid blood parameters do not belong to "the catalogue of benefit of the health insurance fund for health check-up" in Germany. ${ }^{16}$ Therefore, these patients must pay privately unless a specific disease is suspected. ${ }^{17}$ One could speculate whether the possibility of higher profit when seeing private patients influenced the number of patients who were diagnosed this way. ${ }^{18}$ As the diagnosis of a chronic disease is favourably remunerated for physicians in the German health care systems, there might be a lower threshold for diagnosis. The current remuneration system pays doctors for quarterly patient contacts. ${ }^{19}$ Therefore, the financial benefit of repeated consultations of patients with thyroid disease by far outweighs the costs incurred. The current remuneration procedure of the German health system favours uncritical prescription of thyroid hormones.

Our results showed that patients with higher educational background initiated further diagnostic investigation significantly more often than patients with lower educational background. One possible explanation could be that patients with a higher education have more competence and financial funds, thereby being more likely to inform themselves of health topics. ${ }^{19}$ According to observations by Willems et al, patients from higher social classes communicate more actively, show more affective expressiveness, and are more self-confident. As a consequence, these patients were more involved in medical decision making. ${ }^{20}$ In contrast, patients from lower social classes had a more passive role in the communication process. As a result, these patients received less information and fewer examinations. ${ }^{20}$ In addition, participants with a higher educational background were shown to have more health awareness and to exhibit healthier behavior. ${ }^{21}$

We found a broad spectrum of perceived importance of thyroid hormone medication. The importance of medication for the individual patient might be influenced by his or her personal illness conception. ${ }^{22}$ Leventhal et al describe five components that influence illness perception. ${ }^{23}$ Among these they describe, on the one hand, symptoms that patients associate with illness, and, on the other hand, expected consequences and outcomes.

The results of our survey showed that the majority of the patients taking thyroid hormones are female, most of them beyond childbearing age. One possible explanation could be that, in females taking estrogen, higher doses of thyroxine are required. ${ }^{24}$ Bioavailability of thyroxine seems to be lower in female than in male patients. ${ }^{25}$ An alternative hypothesis is the lower health care utilization threshold for women with nonspecific complaints in Germany. ${ }^{26}$ This could result in women being labeled for thyroid disease and prescribed thyroid hormones more frequently than men. Lastly, to lose weight by taking thyroxine might, in some patients, be a reason to press GPs into prescribing thyroxine or to take it longer than indicated.

Permanent thyroxine therapy is not without side effects. Suppressive therapy can cause loss of bone mass. ${ }^{27}$ Therefore, the fact that thyroxine is prescribed uncritically is reason for concern.

\section{Conclusion}

The current remuneration procedure of the German health system favours uncritical prescription of thyroid hormones. In the majority of patients treated with thyroid hormones, doctors had not documented the precise indication for prescription.

\section{Author contributions}

Annika Viniol planned the study design, collected and analyzed data, and wrote the manuscript. Stefan Bösner, Erika Baum, and Norbert Donner-Banzhoff planned and revised the study design. All authors edited the drafted version of the manuscript. 


\section{Acknowledgments}

We thank all attending medical practices, their staff, and all study patients.

\section{Disclosure}

The authors report no conflicts of interest in this work.

\section{References}

1. Schwabe U, Paffrath D. Arzneiverordnungs-Report 2007 [Report of the prescription of pharmaceuticals 2007]. Heidelberg: Springer Medizin Verlag; 2008. German.

2. Melchert HU, Görsch B. Beiträge zur Gesundheitsberichterstattung des Bundes: Schilddrüsenhormone und Schilddrüsenmedikamente bei Probanden in den Nationalen Gesundheitssurveys [Articles about health commentatorship of the federation: Thyroidhormones at participants of the National health survey]. Berlin: Robert-Koch-Institut; 2002. German.

3. Scriba PC, Heseker H, Fischer A. Jodmangel und Jodversorgung in Deutschland [Iodine deficiency and iodine uptake in Germany]. Prävention und Gesundheitsförderung [Prevention and health promotion]. 2009;3:143-148. German.

4. Thamm M, Ellert U. Symposium zur Studie zur Gesundheit von Kindern und Jugendlichen in Deutschland. - Schilddrüsenvergrößerung und Jodverorgung in Deutschland [Symposium of the study about the health of German children and adolescents]. Bundesgesundheitsblatt [Federation health newspaper] 2006, 5/6. German.

5. Villar HC, Saconato H, Valente O, Atallah AN. Thyroid hormone replacement for subclinical hypothyroidism. Cochrane. Database Syst Rev. 2007(3):CD003419.

6. Grussendorf M, Reiners C, Paschke R, Weqscheider K, LISA Investigators. Reduction of thyroid nodule volume by levothyroxine and iodine alone and in combination: a randomized, placebocontrolled trial. Journal of Clinical Endocrinology \& Metabolism. 2011;96(9):2786-2795.

7. Feldkamp J, Seppel T, Muhlmeyer M, et al. [Therapy of endemic goiter with iodide or 1-thyroxine in older patients]. Dtsch Med Wochenschr. 1996;121(51-52):1587-1591. German.

8. Hintze G, Kobberling J. Treatment of iodine deficiency goiter with iodine, levothyroxine or a combination of both. Thyroidology. 1992;4(1):37-40.

9. Kahaly G, Dienes HP, Beyer J, Hommel G. Randomized, double blind, placebo-controlled trial of low dose iodide in endemic goiter. J Clin Endocrinol Metab. 1997;82(12):4049-4053.

10. Lemeshow S, Hosmer DW, Klar J, Lwanga SK. Adequacy of Sample Size in Health Studies. Chichester: John Wiley \& Sons Ltd; 1990.

11. Schnell R, Hill P, Esser E. Methoden der empirischen Sozialforschung [Methods of Social Research Methods]. Munich: Oldenburg Wissenschaftsverlag GmbH; 2008. German.

12. Robinson JC. Theory and practice in the design of physician payment incentives. Milbank Q. 2001;79(2):149-177, III.

13. Kassenärztliche Bundesvereinigung. Empfehlung zur ärztlichen Schweigepflicht, zum Datenschutz und zur Datenverarbeitung in Arztpraxen [Recommendation about the physician confidentiality, data protection and handling in pratices]. Deutsches Ärzteblatt. 2008;105(19): 1026-1030. German.

International Journal of General Medicine

\section{Publish your work in this journal}

The International Journal of General Medicine is an international, peer-reviewed open-access journal that focuses on general and internal medicine, pathogenesis, epidemiology, diagnosis, monitoring and treatment protocols. The journal is characterized by the rapid reporting of reviews, original research and clinical studies across all disease areas.
14. Balint M, Hunt J, Joyce D. Treatment or Diagnosis: A Study of Repeat Prescriptions in General Practice. London: Tavistock Publications Limited; 1970.

15. Ring A, Dowrick C, Humphris G, Salmon P. Do patients with unexplained physical symptoms pressurise general practitioners for somatic treatment? A qualitative study. BMJ. 2004;328(7447):1057.

16. German Federal Joint Committee of doctors and health insurance funds. Berlin: Gesundheitsuntersuchungs-Richtlinien [Health Examination Guidelines] 2008. German.

17. Kassenärztliche Vereinigung Hessen [Association of Statutory Health Insurance Physicians of Hesse]. Laboratoriumsdiagnostische Wunschleistungen [List of individual health services]. Frankfurt: 2009. German.

18. Chaix-Couturier C, Durand-Zaleski I, Jolly D, Durieux P. Effects of financial incentives on medical practice: results from a systematic review of the literature and methodological issues. Int $J$ Qual Health Care. 2000;12(2):133-142.

19. Wangberg SC, Andreassen HK, Prokosch HU, Santana SM, Sørensen T, Chronaki CE. Relations between Internet use, socio-economic status (SES), social support and subjective health. Health Promot Int. 2008; 23(1):70-77.

20. Willems S, De Maesschalck S, Deveugele M, Derese A, De Maeseneer J. Socio-economic status of the patient and doctor-patient communication: does it make a difference? Patient Educ Couns. 2005;56(2):139-146.

21. Gesundheitsberichterstattung des Bundes, Gesundheit in Deutschland [Federal Health Reporting, Health in Germany]. Berlin: Robert-KochInstitut; 2006. German.

22. Weinman J, Petrie KJ, Moss-Morris R, Horne R. The illness perception questionnaire: a new method for assessing the cognitive representation of illness. Psychology Health. 1996;11:431-445.

23. Leventhal H, Nerenz D, Steele DJ. Illness representations and coping with health threats. In Handbook of Psychology and Health. Baum A, Taylor SE, Singer JE, editors. Hillsdale, NJ: Lawrence Erlbaum Associates; 1984:219-252.

24. Alexopoulou O, Beguin C, De Nayer P, Maiter D. Clinical and hormonal characteristics of central hypothyroidism at diagnosis and during followup in adult patients. Eur J Endocrinol. 2004;150(1):1-8.

25. Krehan A, Dittmar M, Hoppen A, Lichtwald K, Kahaly GJ. Randomized, double-blind crossover study of bioavailability of levothyroxine. Med Klin(Munich). 2002;97(9):522-527. German.

26. Schach E, Schwarz FW, Kerek-Bodden HE. Die EVaS-Studie: Eine Erhebung über die ambulante medizinische Versorgung in der Bundesrepublik Deutschland: Daten und Analysen einer bundesweiten Studie des Zentralinstituts für die kassenärztliche Versorgung [The EVaS Study: A Survey of Medical Care in the Federal Republic of Germany: Data and Analysis of a Nationwide Study of the Center for Ambulatory Health Care]. Cologne: Deutscher Ärzteverlag; 1989. German.

27. Mohammadi B, Haghpanah V, Tavangar SM, Larijani B. Modeling the effect of levothyroxine therapy on bone mass density in postmenopausal women: a different approach leads to new inference. Theor Biol Med Model. 2007;4:23.
A key focus is the elucidation of disease processes and management protocols resulting in improved outcomes for the patient.The manuscript management system is completely online and includes a very quick and fair peer-review system. Visit http://www.dovepress.com/ testimonials.php to read real quotes from published authors. 